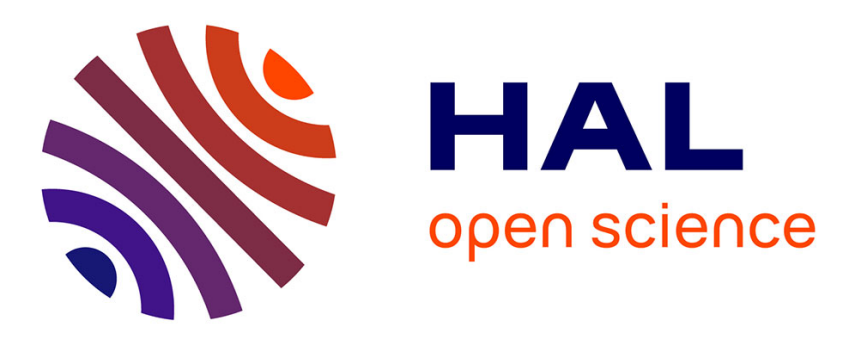

\title{
The Role of the Immune System from an Evolutionary Perspective
}

\author{
Carsten Schradin, Rainer H Straub
}

\section{To cite this version:}

Carsten Schradin, Rainer H Straub. The Role of the Immune System from an Evolutionary Perspective. Schulkin, J. Evolutionary Medicine: Integrating Evolutionary Biology with Clinical Medical Sciences, Oxford University Press, 2020. hal-03007091

\section{HAL Id: hal-03007091 https://hal.science/hal-03007091}

Submitted on 16 Nov 2020

HAL is a multi-disciplinary open access archive for the deposit and dissemination of scientific research documents, whether they are published or not. The documents may come from teaching and research institutions in France or abroad, or from public or private research centers.
L'archive ouverte pluridisciplinaire HAL, est destinée au dépôt et à la diffusion de documents scientifiques de niveau recherche, publiés ou non, émanant des établissements d'enseignement et de recherche français ou étrangers, des laboratoires publics ou privés. 


\section{Chapter 6}

2

3 The Role of the Immune System from an Evolutionary Perspective

4

5 Carsten Schradin ${ }^{1,2}$ and Rainer H Straub ${ }^{3}$

6

$7 \quad{ }^{1}$ Université de Strasbourg, CNRS, IPHC UMR 7178, F-67000 Strasbourg, France

$8 \quad{ }^{2}$ School of Animal, Plant and Environmental Sciences, University of the Witwatersrand,

9 Johannesburg, South Africa

$10 \quad{ }^{3}$ Laboratory of Experimental Rheumatology and Neuroendocrine Immunology, Depart-

11 ment of Internal Medicine, University Hospital Regensburg, Germany

\section{Corresponding author.}

15 Prof. Dr. Rainer H Straub

Laboratory of Experimental Rheumatology and Neuroendocrine Immunology

Department of Internal Medicine

University Hospital Regensburg

19 F.J.Strauss-Allee 11

2093053 Regensburg, Germany

Email R. Straub: rainer.straub@ukr.de

Email: Carsten.schradin@iphc.cnrs.fr

Page heading: Immune system

Word count abstract: 231

Word count text: 3258

Number of tables and figures: 3

Number of boxes: 0 


\section{ABSTRACT}

"Nothing in Biology makes sense, except in the light of evolution." This famous citation of Theodosius Dobzhansky also underlies the integrative field of evolutionary medicine, which faces the challenge to combine (patho-)physiological mechanisms with evolutionary function. Here we introduce a concept from the study of animal behaviour, which are the four questions of Tinbergen that consider 1) the ontogeny of an individual describing its development, 2) its physiological machinery, which 3) has fitness consequences influencing 4) the evolutionary history (phylogeny) of future generations. It is shown how this concept can be applied to infectious disease and to chronic inflammatory systemic diseases. Evolutionary medicine takes lifetime reproductive success into account. The hypothesis to be tested is that mechanisms underlying a disease in old age might have higher fitness benefits in the pre-reproductive and / or reproductive life history stage. We emphasize that our human aim is not to increase evolutionary fitness but to reduce suffering and costs of public health. Thus, medical research might be most successful in diseases that have no lifetime fitness cost, as otherwise evolution would already have acted against it. Importantly, while no selection pressure existed to favour physiological mechanisms acting against such diseases, such mechanisms might become available via biomedical research. We conclude that for a comprehensive understanding of the pathophysiology of a disease, its fitness consequences and its evolutionary history should be considered. The special situation of the immune system and chronic inflammatory systemic diseases is highlighted.

KEYWORDS: evolutionary fitness; life history; reproductive success; disease; public health 


\subsection{INTRODUCTION}

Evolutionary medicine emphasizes that to better understand modern human health and disease, the underlying evolutionary history and evolutionary consequences must also be understood. Thus, evolutionary medicine will contribute significantly to our understanding of the fitness consequences and the phylogeny (evolutionary history) of diseases and disease related traits, explaining why disease exist even though it reduces fitness (Gluckman et al. 2009, Perlman 2013, Stearns et al. 2016).

For example, when trying to understand why chronic inflammatory systemic diseases (CIDs) occur, evolutionary biologists pointed out that it is crucial to consider the effect of CIDs on lifetime reproductive success depending on the species-specific life history traits such as age at first reproduction, reproductive lifespan, and life expectancy (Straub et al. 2016). However, evolutionary medicine faces the challenge and difficulty to integrate physiological mechanisms with evolutionary function (Gluckman et al. 2009, Lozano 2010, Nesse et al. 2012). This challenge is not unique to evolutionary medicine, but is one of the main topics in organismal research in biology, and has been especially addressed in the research on animal behaviour (Tinbergen 1963).

Biological research has traditionally been divided into the study of proximate (physiological or pathophysiological) mechanisms on the one hand and ultimate (evolutionary) causes on the other hand (Mayr 1961). Most researchers take only one of these two approaches into account (Drickamer 1998). For example, immunological research is mainly proximate, focusing on the pathophysiological mechanisms underlying the most prevalent infectious diseases, allergic diseases, and CIDs. Studies in behavioural ecology, on the other hand, are primarily ultimate, focusing on the fitness consequences of behaviour, which means whether individuals showing a specific behaviour have more offspring than other individuals (Krebs et al. 1993, Wilson 1975). Behavioural ecologists have realized that studying physiological mechanisms as evolved traits that increase fitness provides an integrative understanding of animal behaviour (Wikelski et al. 2001, Wingfield 2008).

For example, the major histocompatibility complex (MHC), a molecule that plays a significant role in the immune response (a proximate factor), is known to affect behaviour, enabling females to choose mates with complementary MHC alleles, which increases fitness of common offspring (Kamiya et al. 2014, Lerner et al. 1991). Thus, behavioural ecologists came to a more comprehensive understanding of behaviour by taking into account the fitness consequences of its underlying physiological mechanisms. 
Based on the four questions of Tinbergen that he applied to animal behaviour (Tinbergen 1963), we want to tackle the role of the immune system from an evolutionary perspective. This will be addressed in this chapter by using the special situation of CIDs as an example.

\subsection{THE FOUR QUESTIONS OF TINBERGEN}

Tinbergen formulated in 1963 four questions (Tinbergen 1963), which are the basis for an integrative approach to understand biological traits (Krebs et al. 1993). Each question is of equal importance. The four questions are (see also (Bateson et al. 2013, Nesse 2013)):

- What is the Function, which means the fitness value of the trait?

- What is the Phylogeny, which means the evolutionary history of the trait?

- How did the trait develop in individuals over their lifetime (Ontogeny)?

- What physiological machinery causes the observable trait (Causation)?

The questions concerning the function and phylogeny address ultimate factors, whereas questions concerning ontogeny and causation address proximate factors. Evolutionary medicine focusses on the two ultimate factors. The question about the function concerns the fitness consequences of behavioural patterns, i.e., why did they evolve? In order to evolve through the process of natural selection, a specific trait must have fitness benefits for the individual, which means increase the number of offspring produced during the individual's lifetime. The question regarding the phylogeny of a trait concerns the evolutionary history. Tinbergen regarded the responding central nervous system as the machinery causing animal behaviour. He defined ontogeny of behaviour as the "change of behavioural machinery during development". Thus, the question addressing causation is the question about the behavioural machinery leading to the observed behavioural pattern, and the question about ontogeny asks how this machinery develops until the behaviour is shown for the first time (Tinbergen 1963). In the context of an immune response, this machinery is called the "immune machinery." (1) 


\subsection{THE FOUR QUESTIONS OF TINBERGEN AND THE IMMUNE RESPONSE}

\subsubsection{Function - fitness value of the trait}

Reactions to acute inflammation serve the body to overcome short-lived infectious diseases and other threats such as exposure to allergic antigens. In both situations, the bod tries to get rid of the stimulus. The mechanisms are thus adaptive, increasing individual fitness. Typically, inflammatory responses are highly adaptive, enabling individuals to overcome infections, to combat allergic threats, and to heal wounds. Thus, alleles of genes enabling this adaptive response got fixed within the gene pool.

Thanks to the last two decades of genome-wide association studies, we now recognize that hundreds of genetic loci associated with CIDs overlap with genes relevant in infectious and allergic diseases (Brinkworth et al. 2014). While in earlier time (before 2000), CIDs were thought to have one unique immune disease pathways, it is now very clear that this is incorrect. In CIDs inflammation is typically regulated by a network of genes that are implicated in multiple diseases (Cotsapas et al. 2011). The unique disease pathway is known in monogenic autoinflammatory diseases, which also employ immune pathways relevant to infections and allergies.

\subsubsection{Phylogeny - evolutionary history of the trait}

The evolutionary history of human immunological pathways is shared with sharks, birds, and rodents, spanning more than 420 million years (Boehm 2011). The best known association between infections and genes has been established for the MHC allele system, which is an important element of antigen presentation in the human leukocyte antigen molecules (HLA). Polymorphic MHC alleles have been retained because they helped to overcome various infections (Mangalam et al. 2013), leading to positive selection. For example, the genetic factor HLA-DR4 (DRB1*04) protects from dengue hemorrhagic fever (LaFleur et al. 2002). Furthermore, clearance of virus infections is much better for hepatitis $B$ virus in the presence of HLA-DR13 (Wang et al. 2016) and for human immunodeficiency virus in the presence of HLA-B27 (Chakrabarti et al. 2010). There are many more examples also outside the MHC allele system, presentation of which would go beyond the scope of this chapter. The reader is referred to important reviews (Brinkworth et al. 2014). 
6.3.3 Ontogeny - development of the trait in individuals over a lifetime The environment of an individual during development and adult life together with the genotype determine how the inflammatory response system develops and will later respond. The immune system is equipped with a system to memorize antigens, and this influences its later responsiveness to the same antigens. We call it immunological memory (Murphy et al. 2011), which is very personal depending on the exposure of the individual to infectious agents during the lifetime. For example, most people in Europe have been exposed to small pox virus and are thus immune to it. This was completely different for native Americans at a time point of arrival of European seafarers in the $16^{\text {th }}$ century, leading to mass extinction of local inhabitants (Patterson et al. 2002).

Another example in the neuroendocrine immune field further demonstrates the impact of ontogeny. Neonatal exposure of a new-born rat to lipopolysaccharide changes the hypothalamic-pituitary adrenal axis markedly (Shanks et al. 1995). As adults, neonatally endotoxin-treated animals exhibited significantly greater adrenocorticotrophic hormone and corticosterone responses to restraint stress than controls. Neonatal endotoxin treatment reduced glucocorticoid receptor density across a wide range of brain regions (Shanks et al. 1995). Exposure to gram-negative lipopolysaccharide in early life can alter the development of neural systems, which govern endocrine responses to stress and may thereby predispose individuals to stress-related pathology. Indeed, it has been demonstrated that neonatal endotoxin treatment of rats protects animals from experimental arthritis later in life (Shanks et al. 2000). This long-term imprinting of central nervous changes in the early phase of ontogeny can also change the behaviour of the immune system throughout life.

\subsubsection{Causation - the "immune machinery"}

Inflammation is caused by specific antigens, including pathogens or cell material of damaged tissue (wounds), to which the immune system responds (Murphy et al. 2011). There are several supportive reactions of the neuronal and endocrine systems that foster the immune response in acute infectious diseases (Straub 2015), altogether representing the causation of inflammation and immune response. In line with Tinbergen's terminology (i.e., behavioural machinery), this might be called the immune machinery. The immune machinery consists of immune cells (neutrophils, lymphocytes, macrophages, dendritic cells, natural killer cells, and many others) with specific surface receptors to activate these cells, causing the release of inflammatory mediators (Murphy et al. 2011). 
The immune machinery is highly dependent on the availability of energy-rich substrates in the body because immune cells demand enormous amounts of energy (Gaber et al. 2017, Straub et al. 2010). We may call the immune system selfish, because during infection it is the major dominating factor operating at the highest hierarchical level to acquire energyrich substrates (Straub 2014). This selfishness has been positively selected for infectious diseases, and it is an important determining aspect of the immune machinery (causation).

\subsubsection{Integrative approach - the immune system in evolutionary medicine (Fig 1)} The immune machinery has been positively selected for short-lived infectious diseases (causation), which leads to measurable immune responses and inflammation (diagnostic, red box in Fig. 1), protecting the individual from infections / helping during wound healing. This increases the chance of survival and reproduction at a later stage, increasing evolutionary fitness (Schmid-Hempel 2011). Genes improving the immune response increased in frequency in the gene pool (phylogeny). The individual genotypes together with the individual specific environment lead to an individual specific development of the immune system (ontogeny). A classical ontogenetic factor of the immune response is immunological memory of the adaptive immune system towards pathogen-specific antigens (Murphy et al. 2011). If a microbial antigen is known to the immune machinery (causation), then it is rapidly activated, i.e. an immediate response towards an infectious agent is generated. The immune machinery with memory consists of educated specific T or B cells (physiological response) that can be observed as a phenotypic trait, causing a stronger and faster immune reaction towards the antigen (causation).

Figure 1 here

\subsection{THE FOUR QUESTIONS OF TINBERGEN AND CHRONIC INFLAMMA- TORY SYSTEMIC DISEASES}

CIDs are characterized by a continuous immune response towards harmless autoantigens (reaction against innocuous self) or harmless microbes on the surface of the body (reaction against innocuous foreign) (Firestein et al. 2013). Examples for CIDs are rheumatoid arthritis, multiple sclerosis, ankylosing spondylitis, systemic lupus erythematosus, Sjögren syndrome, pemphigus vulgaris, and many others. While an immune response is usually 
confined to a small space, it becomes chronic and widespread in CIDs (Hochberg et al. 2015, Straub 2015). A CID leads to new energy requirements in an affected person, which supports many unwanted disease-related signs and symptoms recently demonstrated (Straub et al. 2016).

\subsubsection{Ultimate factors - Function and Phylogeny}

While reactions to acute inflammation serve the body to overcome short-lived infectious diseases (see 6.3.1), a long-term CID is detrimental. In CIDs, the positively selected immune mechanisms, which usually support fitness and function (Fig, 1), are continuously activated by harmless antigens, and the response becomes maladaptive (Straub et al. 2016). Importantly, a CID - while costly - will not have a significant influence on fitness (function), because it typically happens after the reproductive phase (Fig. 2).

Figure 2 here

CIDs have a multifactorial genetic background discussed above (section 6.3.1). The MHC allele system plays an important role in CIDs. For some MHC alleles, the risk to develop a CID is 90 times increased (Brewerton et al. 1973, Schlosstein et al. 1973). However, negative selection against specific MHC alleles was most probably weak, because in most individuals carrying these alleles the disease did not develop due to the lack of additional risk factors (Straub et al. 2016) that are important during ontogeny. MHC alleles were positively selected due their role in infection (see section 6.3.2). We described the link between HLA-DR4 (DRB 1*04) and dengue hemorrhagic fever, but the same MHC allele is known to be positively associated with rheumatoid arthritis, type I diabetes mellitus, and other CIDs.

We described HLA-B27 as an important factor to overcome human immunodeficiency virus infection (see section 6.3.2), but the same allele is linked to ankylosing spondylitis (Brewerton et al. 1973, Schlosstein et al. 1973). Thus, many traits have an evolutionary history (phylogeny) developed in the context of infectious disease, but these traits are used again in another somatic environment in later life (Williams 1957). This phenomenon is called antagonistic pleiotropy (Williams 1957), which means fitness benefits at one life history stage being higher than fitness costs at another life history stage. Here, they can support the development of a CID. 
6.4.2 Ontogeny - development of the trait in individuals over a lifetime

We learned that the immune system has a memory for antigens. However, cross-reactivity towards harmless autoantigens (reaction against innocuous self) or harmless microbes on the surface of the body (reaction against innocuous foreign) as in CIDs can also occur. Now, the immune memory is directed against the harmless antigens, which leads to a chronic immune attack in CIDs.

Sometimes autoantigens are posttranslationally processed, which can be supported by factors that appear during individual development. For example, smoking may change selfpeptides leading to an exchange of arginine with citrulline (Quirke et al. 2011). This posttranslational modification with the new citrulline is foreign to the immune system and may be attacked as an antigen. Thus, smoking is one environmental factor during development known to increase the risk that the immune system later attacks harmless autoantigens fostering CIDs (Klareskog et al. 2011, Mathews et al. 1973). Another environmental risk factor for some CIDs is silica exposure, for example during construction work, which might overstimulate the immune system and trigger the autoimmune process leading to chronic inflammation (Pollard 2016).

Another environmental risk factor is psychological stress. We already saw that neonatal endotoxin exposure can change the adult immune system response, and it seems that the childhood immune system is more vulnerable to stressors as compared to the adult immune system (see 6.3.3). In several studies, it was demonstrated that childhood trauma (death of a parent, sexual abuse, violence in the family etc.) was positively linked to later appearance of CIDs (Dube et al. 2009, Neufeld et al. 2013, Spitzer et al. 2013). These examples are indicative of how the individual development can manipulate the immune system and the appearance of overt CIDs.

\subsubsection{Causation - the immune machinery}

In CIDs, the role of the immune machinery was described for more than 100 years, reaching enormous detail since the start of molecular biology and functional genomics in the 1980s and 1990s. Today, we realize that many important pathways have been discovered that cause and support CIDs (Firestein et al. 2013, Hochberg et al. 2015). These novel factors led to the development of biological therapy such as anti-TNF strategies (Feldmann et al. 2010). Nevertheless, much detail needs to be learned, particularly, with respect to human CIDs. Importantly, the immune machinery for CIDs is the same as the immune machinery for infectious diseases and allergy. 
On top of the specific immune machinery, which was called selfish (see 6.3.4), a general bodily reaction supports the immune system (Straub et al. 2013). The immune system is selfish because it makes use of other systems (nervous and endocrine) to redistribute energy-rich fuels (Straub 2014). While this has been positively selected for short-lived infectious diseases, the long-term application of these adaptive programs leads to many unfavourable signs and symptoms in CIDs (Straub et al. 2016). These are daytime fatigue, low mood, sleeping alterations, anorexia, inflammation type of anaemia, muscle loss (sarcopenia), bone loss, insulin resistance, decreased fertility $\&$ libido, high blood pressure $\&$ volume overload, and increased blood coagulation (Straub et al. 2016). These phenomena were positively selected as the non-immune machinery that supports the immune machinery. However, if the non-immune machinery is used too long, many problems appear that need specific extra treatment besides immunosuppression. Long-term use of these programs is maladaptive (Straub et al. 2016).

\subsubsection{Integrative approach to understand CIDs in evolutionary medicine (Fig. 3)}

Ultimate factors have been positively selected for short-lived infectious diseases and not for CIDs (Straub et al. 2016). Net fitness is increased because the fitness benefits in early life are much higher than fitness costs in post-reproductive life, so that favourable genes stay in the gene pool (function and phylogeny). The individual genotypes together with the individual specific environment lead to an individual specific development of the immune system (ontogeny). Here, environmental factors such as smoking, silica exposure, and childhood stress can prepare the immune machinery for the unfortunate development of a CID. When several factors come together (genetic \& environmental), the individual can develop an immune response towards harmless self and harmless foreign antigens. Then, the response is imprinted in the immune memory, which leads to measurable immune responses such as autoantibodies towards citrullinated peptides (diagnostic, red box in Fig. $3)$.

Figure 3 here

\section{CONCLUSIONS: APPLICATION OF THE FOUR QUESTIONS OF TINBERGEN IN EVOLUTIONARY MEDICINE}

Many chronic diseases might be studied and understood using the same framework as outlined in figure 3 . The evolutionary approach here considers three points: 
1. One must take into account the fitness consequences of the trait leading to disease

2. To be done at the different life history stages (pre-reproduction, reproductive age, and post-reproductive; Fig. 2)

3. To determine life-time reproductive success

This will enable us to understand the evolutionary history of the disease, especially why alleles favouring the disease have been established in the gene pool. This approach might then also benefit clinicians: it is often less relevant to know which genes and alleles favour the expression of a specific disease, but the environmental factors triggering the disease. This is because we cannot easily change the genotype of individuals, but we can interfere with environmental threats in the individual live.

Finally, the absence of physiological mechanism acting against a disease is no indicator that such a mechanism is impossible; it only indicates that such a mechanism would not significantly increase fitness. However, our human aim is to reduce suffering and costs of public health, not to increase evolutionary fitness. This leads to the conclusion that biomedical research might be most successful in diseases that have no or low lifetime fitness cost, but high costs for public health and a high load of individual suffering.

Last but not least, current research topics in evolutionary medicine where our graphical model might fail could nevertheless benefit by taking the four questions into account. Examples could be maladaptation, environmental mismatch and evolved traits that are not adaptive in the current modern environment. By applying the model and then identifying where it fails, the reason as well as the consequences why the trait is not adaptive or why environmental mismatch occurs could be identified. Thus, not all disease can be explained and described by Tinbergen`s four question, but identifying why and when this concept fails will nevertheless improve our understanding why our body is constructed in a way that sometimes leads to disease.

Funding and conflict of interest: The authors have no conflict of interest. CS was supported by the CNRS, RS by the University of Regensburg. 


\section{References}

Bateson, P. and Laland, K.N. (2013). Tinbergen's four questions: an appreciation and an update. Trends Ecol. Evol., 28, 712-8.

Boehm, T. (2011). Design principles of adaptive immune systems. Nat. Rev. Immunol., 11, 307-17.

Brewerton, D.A., Hart, F.D., Nicholls, A., Caffrey, M., James, D.C. and Sturrock, R.D. (1973). Ankylosing spondylitis and HL-A 27. Lancet., 1, 904-7.

Brinkworth, J.F. and Barreiro, L.B. (2014). The contribution of natural selection to present-day susceptibility to chronic inflammatory and autoimmune disease. Curr. Opin. Immunol., 31, 66-78.

Chakrabarti, L.A. and Simon, V. (2010). Immune mechanisms of HIV control. Curr. Opin. Immunol., 22, 488-96.

Cotsapas, C., Voight, B.F., Rossin, E., Lage, K., Neale, B.M., Wallace, C., Abecasis, G.R., Barrett, J.C., Behrens, T., Cho, J., De Jager, P.L., Elder, J.T., Graham, R.R., Gregersen, P., Klareskog, L., Siminovitch, K.A., van Heel, D.A., Wijmenga, C., Worthington, J., Todd, J.A., Hafler, D.A., Rich, S.S., Daly, M.J. and FOCiS Network of Consortia (2011). Pervasive sharing of genetic effects in autoimmune disease. PLoS. Genet., 7, e1002254.

Drickamer, L.C. (1998). Vertebrate behavior: integration of proximate and ultimate causation. American Zoologist, 38, 39-42.

Dube, S.R., Fairweather, D., Pearson, W.S., Felitti, V.J., Anda, R.F. and Croft, J.B. (2009). Cumulative childhood stress and autoimmune diseases in adults. Psychosom. Med., 71, 243-50.

Feldmann, M., Williams, R.O. and Paleolog, E. (2010). What have we learnt from targeted anti-TNF therapy? Ann. Rheum Dis., 69 (Suppl 1), i97-i99.

Firestein, G.S., Kelley, W.N., Budd, R.C., Gabriel, S.E., McInnes, I.B. and O'Dell, J.R. (2013). Kelley's textbook of rheumatology. Elsevier/Saunders, Philadelphia, PA.

Gaber, T., Strehl, C. and Buttgereit, F. (2017). Metabolic regulation of inflammation. Nat. Rev. Rheumatol., 13, 267-79.

Gluckman, P., Beedle, A. and Hanson, M. (2009). Principles of evolutionary medicine. Oxford University Press, Oxford New York.

Hochberg, M.C., Silman, A.J., Smolen, J.S., Weinblatt, M.E. and Weisman, M.H. (2015). Rheumatology. Elsevier Mosby, Philadelphia.

Kamiya, T., O'Dwyer, K., Westerdahl, H., Senior, A. and Nakagawa, S. (2014). A quantitative review of MHC-based mating preference: the role of diversity and dissimilarity. Mol. Ecol., 23, 5151-63.

Klareskog, L., Malmstrom, V., Lundberg, K., Padyukov, L. and Alfredsson, L. (2011). Smoking, citrullination and genetic variability in the immunopathogenesis of rheumatoid arthritis. Semin. Immunol., 23, 92-8.

Krebs, J.R. and Davies, N.B. (1993). An Introduction to Behavioural Ecology. Blackwell Science Ltd., Oxford.

LaFleur, C., Granados, J., Vargas-Alarcon, G., Ruiz-Morales, J., Villarreal-Garza, C., Higuera, L., Hernandez-Pacheco, G., Cutino-Moguel, T., Rangel, H., Figueroa, R., Acosta, M., Lazcano, E. and Ramos, C. (2002). HLA-DR antigen frequencies in Mexican patients with dengue virus infection: HLA-DR4 as a possible genetic resistance factor for dengue hemorrhagic fever. Hum. Immunol., 63, $1039-44$. 
Lerner, S.P. and Finch, C.E. (1991). The major histocompatibility complex and reproductive functions. Endocr. Rev., 12, 78-90.

Lozano, G.A. (2010). Evolutionary explanations in medicine: how do they differ and how to benefit from them. Med. Hypotheses., 74, 746-9.

Mangalam, A.K., Taneja, V. and David, C.S. (2013). HLA class II molecules influence susceptibility versus protection in inflammatory diseases by determining the cytokine profile. Journal of Immunology, 190, 513-8.

Mathews, J.D., Whittingham, S., Hooper, B.M., Mackay, I.R. and Stenhouse, N.S. (1973). Association of autoantibodies with smoking, cardiovascular morbidity, and death in the Busselton population. Lancet., 2, 754-8.

Mayr, E. (1961). Cause and effect in biology. Science, 134, 1501-6.

Murphy, K.M., Travers, P. and Walport, M. (2011). Janeway's Immunobiology. Taylor \& Francis, Oxford.

Nesse, R.M. (2013). Tinbergen's four questions, organized: a response to Bateson and Laland. Trends in Ecology \& Evolution, 28, 681-2.

Nesse, R.M., Ganten, D., Gregory, T.R. and Omenn, G.S. (2012). Evolutionary molecular medicine. J Mol. Med. (Berl)., 90, 509-22.

Neufeld, K.M., Karunanayake, C.P., Maenz, L.Y. and Rosenberg, A.M. (2013). Stressful life events antedating chronic childhood arthritis. J Rheumatol., 40, 1756-65.

Patterson, K.B. and Runge, T. (2002). Smallpox and the Native American. Am. J Med. Sci., 323, 216-22.

Perlman, R.L. (2013). Evolution \& Medicine. Oxford University Press, Oxford.

Pollard, K.M. (2016). Silica, Silicosis, and Autoimmunity. Front Immunol., 7, 97.

Quirke, A.M., Fisher, B.A., Kinloch, A.J. and Venables, P.J. (2011). Citrullination of autoantigens: upstream of TNFalpha in the pathogenesis of rheumatoid arthritis. FEBS Lett., 585, 3681-8.

Schlosstein, L., Terasaki, P.I., Bluestone, R. and Pearson, C.M. (1973). High association of an HL-A antigen, W27, with ankylosing spondylitis. N. Engl. J Med., 288, 704-6.

Schmid-Hempel, P. (2011). Evolutionary parasitology. Oxford University Press, Oxford.

Shanks, N., Larocque, S. and Meaney, M.J. (1995). Neonatal endotoxin exposure alters the development of the hypothalamic-pituitary-adrenal axis: early illness and later responsivity to stress. $J$ Neurosci., 15 , 376-84.

Shanks, N., Windle, R.J., Perks, P.A., Harbuz, M.S., Jessop, D.S., Ingram, C.D. and Lightman, S.L. (2000). Early-life exposure to endotoxin alters hypothalamic-pituitary-adrenal function and predisposition to inflammation. Proc. Natl. Acad. Sci. U. S. A, 97, 5645-50.

Spitzer, C., Wegert, S., Wollenhaupt, J., Wingenfeld, K., Barnow, S. and Grabe, H.J. (2013). Gender-specific association between childhood trauma and rheumatoid arthritis: a case-control study. J Psychosom. Res., 74, 296-300.

Stearns, S.C. and Medzhitov, R. (2016). Evolutionary medicine. Sinauer Associates, Inc., Sunderland, MA.

Straub, R.H. (2014). Insulin resistance, selfish brain, and selfish immune system: an evolutionarily positively selected program used in chronic inflammatory diseases. Arthritis Res. Ther., 16(Suppl 2), S4 (pages $1-15)$.

Straub, R.H. (2015). The origin of chronic inflammatory systemic diseases and their sequelae. Academic Press, San Diego. 
Straub, R.H., Bijlsma, J.W., Masi, A. and Cutolo, M. (2013). Role of neuroendocrine and neuroimmune mechanisms in chronic inflammatory rheumatic diseases-The 10-year update. Semin. Arthritis Rheum., 43, 392-404.

Straub, R.H., Cutolo, M., Buttgereit, F. and Pongratz, G. (2010). Energy regulation and neuroendocrineimmune control in chronic inflammatory diseases. J Intern. Med., 267, 543-60.

Straub, R.H. and Schradin, C. (2016). Chronic inflammatory systemic diseases: An evolutionary trade-off between acutely beneficial but chronically harmful programs. Evol Med. Public Health., 2016, $37-$ 51.

Tinbergen, N. (1963). On aims and methods of ethology. Zeitschrift für Tierpsychologie, 20, 410-33.

Wang, L., Zou, Z.Q. and Wang, K. (2016). Clinical Relevance of HLA Gene Variants in HBV Infection. J Immunol. Res., 2016, 9069375.

Wikelski, M. and Ricklefs, R.E. (2001). The physiology of life histories. Trends in Ecology \& Evolution, 16, 479-81.

Williams, G.C. (1957). Pleiotropy, natural selection, and the evolution of senescence. Evolution, 11, 398-411.

Wilson, E.O. (1975). Sociobiology: The new Synthesis. Harvard University Press, Cambridge, MA.

Wingfield, J.C. (2008). Comparative endocrinology, environment and global change. Gen. Comp Endocrinol., 157, 207-16. 